\title{
Implementation Intentions and Disengagement from a Failing Course of Action
}

\author{
MARLONE D. HENDERSON ${ }^{1 *}$, PETER M. GOLLWITZER ${ }^{2,3}$ \\ and GABRIELE OETTINGEN ${ }^{2,4}$ \\ ${ }^{1}$ Department of Psychology, University of Chicago, Illinois, USA \\ ${ }^{2}$ Department of Psychology, New York University, New York, USA \\ ${ }^{3}$ University of Konstanz, Germany \\ ${ }^{4}$ University of Hamburg, Germany
}

\begin{abstract}
We explored the consequences of forming implementation intentions that call for action (adjustment of chosen course of action) versus reflection (assessment of the appropriateness of chosen course of action) in situations that activate people's tendency to remain committed to failing courses of action. In Study 1, when negative experiences preceded failure, action and reflection implementation intention participants showed higher rates of disengagement than mere goal intention and no intention participants. However, when positive experiences preceded failure, only action implementation intention participants maintained this high disengagement rate. In Study 2, we observed that time pressure moderated the facilitating effects of action and reflection implementation intentions on disengagement when negative experiences preceded failure. Whereas the effect of action implementation intentions benefited from time pressure, the effect of reflection implementation intentions did not. The present studies construe disengagement as a self-regulation process and highlight the benefits of implementation intentions as a self-regulation tool. Copyright (C) 2006 John Wiley \& Sons, Ltd.
\end{abstract}

KEY WORDS escalation of commitment; self-regulation; disengagement; goals; plans; time pressure; arousal

\section{INTRODUCTION}

Various lines of research have highlighted the many difficulties associated with goal pursuit. For example, Gollwitzer $(1993,1996)$ has focused on the problems that people encounter as they try to get started on their goal-directed behavior. He points out that people often fail to recognize good opportunities to act on their goals because they are highly absorbed in ongoing activities, wrapped up in demanding ruminations, gripped

* Correspondence to: Marlone D. Henderson, Department of Psychology, 5848 S. University Avenue, University of Chicago, Chicago, IL 60637, USA. E-mail: mhenderson@uchicago.edu 
by intense emotional experiences, or simply tired. Others have concentrated on the problem of maintaining an ongoing goal pursuit. The maintenance of goal striving is frequently disrupted by attractive distractions (Metcalfe \& Mischel, 1999), conflicting bad habits (Verplanken \& Faes, 1999), and detrimental self-states (e.g., self-definitional incompleteness, Gollwitzer \& Wicklund, 1985; depleted cognitive resources, Muraven, Tice, \& Baumeister, 1998).

\section{IMPLEMENTATION INTENTIONS}

Over the last decade, research (summaries by Gollwitzer, 1999; Gollwitzer, Bayer, \& McCulloch, 2005; Gollwitzer \& Sheeran, 2006) has shown that asking people to adopt self-instructions that involve furnishing goals with implementation intentions (if-then plans) helps people get started on their goals as well as maintain their ongoing goal pursuits. Whereas goals have the structure of "I intend to achieve or reach Z" with Z referring to a desired outcome or behavior to which one feels committed, implementation intentions have the structure of "If situation X is encountered, then I will perform behavior Y!" Through making if-then plans, mental links are formed between anticipated critical situations or opportunities and select goal-directed responses that place people's goal-directed thoughts, feelings, and behavior under direct situational control. This situational control fosters automatic goal pursuit, that is, goal pursuit that is not only successful but also immediate (Orbell \& Sheeran, 2000), efficient (Brandstätter, Lengfelder, \& Gollwitzer, 2001), and free of conscious intent (U. C. Bayer, G. B. Moskowitz, \& P. M. Gollwitzer, 2002. Implementation, intentions and action initiation without conscious intent. University of Konstanz, Germany. Unpublished manuscript.) once the critical situation is encountered (see Aarts \& Dijksterhuis, 2000 and Verplanken \& Faes, 1999, who point to the similarities between action control by implementation intentions and habitual action control).

\section{DISENGAGEMENT FROM A FAILING COURSE OF ACTION}

While research centered on the self-regulation of goal pursuit has mainly concentrated on problems associated with initiating and maintaining goal-directed behavior, there are also problems of goal pursuit that have to do with finding a proper ending (Carver \& Scheier, 1999; Wrosch \& Heckhausen, 1999). For instance, there is the issue of disengaging from a goal pursuit that has gone foul. While researchers have studied this failure to disengage under varying labels, namely sunk costs (e.g., Arkes \& Blumer, 1985), entrapment (e.g., Brockner, Rubin, \& Lang, 1981), and escalation (e.g., Tan \& Yates, 2002), the basic conceptualization of the phenomenon is similar (Bragger, Hantula, Bragger, Kirnan, \& Kutcher, 2003). According to Staw and Ross (1987, pp. 40), “escalation situations can be defined as predicaments where costs are suffered in a course of action, where there is an opportunity to withdraw or persist, and when the consequences of persistence and withdrawal are uncertain."

Escalation effects have typically been demonstrated with decisions about how to allocate money (Bragger et al., 2003), time (Rubin, Brockner, Small-Weil, \& Nathanson, 1980), and effort (Aspinwall \& Richter, 1999). ${ }^{1}$ Escalation is typically assessed in terms of decisions about when to stop allocating something (progress decisions) or decisions involving a choice of whether to use or undertake something (adoption decisions); such situations can involve either a single decision (e.g., Moon, 2001a) or repeated decisions (e.g., McCain, 1986; Staw \& Fox, 1977). Several explanations for the escalation effect have been offered, including loss aversion (Whyte, 1986, 1993), self-presentational concerns (Brockner et al., 1981), project completion

\footnotetext{
${ }^{1}$ Escalation of commitment has been found to occur for decisions that do not involve personal resources. In particular, Schoorman (1988) found escalation effects for decisions regarding appraisals of others' performance.
} 
concerns (Garland \& Conlon, 1998; Moon, 2001a), and uncertainty reduction (Bragger et al.). While the search for the best account of escalation still continues (e.g., Moon), some researchers have concluded that the phenomenon cannot be explained by a single model (e.g., Brockner, 1992; Moon).

Rather than focusing on the causes or antecedents of escalation, many organizational and applied psychologists have examined a host of moderators of the escalation effect, including prior success versus failure experience (Bragger et al., 2003), low versus high efficacy of using one's resources (Staw \& Fox, 1977), passive versus active resource allocation (Brockner, Shaw, \& Rubin, 1979; Rubin et al., 1980), public versus private limit setting (Brockner et al.), positive versus negative framing of decision alternatives (Davis \& Bobko, 1986; Schoorman, Mayer, Douglas, \& Hetrick, 1994), social versus nonsocial decision contexts (Dietz-Uhler, 1996; Rubin et al., 1980) ${ }^{2}$, and the presence versus absence of alternative courses of action (Aspinwall \& Richter, 1999; McCain, 1986). In addition, investigators have discovered personality characteristics that either attenuate or augment escalation effects, including Type A personality (Schaubroeck \& Williams, 1993), dispositional optimism (Aspinwall \& Richter), and conscientiousness (Moon, 2001b).

\section{IMPLEMENTATION INTENTIONS AND DISENGAGEMENT}

Importantly, investigators have also examined the effects of using financial budgets on escalation (Heath, 1995; Tan \& Yates, 2002). This prior work highlights that disengagement intentions formed in advance may actually enable individuals to overcome escalation tendencies. If one assumes that disengagement from a chosen course of goal-directed action rather than escalation of commitment is often appropriate and even necessary in order for goal pursuit to be successful (Brandstäter \& Frank, 2002; Carver \& Scheier, 1999; Gollwitzer, 1990; Wrosch \& Heckhausen, 1999; Wrosch, Scheier, Carver, \& Schulz, 2003; Wrosch, Scheier, Miller, Schulz, \& Carver, 2003), forming in advance intentions to disengage from a failing course of action qualifies as an important self-regulation strategy. As Gollwitzer and Moskowitz (1996) pointed out, a successful goal-directed organism must be able to respond flexibly to variations in stimuli connected with goals. Thus, we see the unwillingness to disengage from a failing course of goal-directed action as a self-regulatory problem, and argue that such escalation tendencies should be effectively countered with appropriate self-regulatory strategies.

\section{Pilot study}

Recently, we (Henderson, Gollwitzer, \& Oettingen, 2003) presented findings that suggest that escalation effects will be reduced through the use of implementation intentions that specify switching to a different course of action. We hypothesized that participants who relied on the self-regulatory strategy of forming implementation intentions would be comparatively more effective in reducing escalation effects as compared to participants who relied on the weaker self-regulatory strategy of simply setting goal intentions (to avoid the escalation of commitment to a chosen course of action by always intending to pursue the best course of action) or no self-regulatory strategy at all (Gollwitzer, 1999). In order to test our hypotheses, we used a research paradigm that has been shown to create a strong escalation tendency by stimulating the self-justification motive (Aronson, 1968; Festinger, 1957; Staw, 1976).

Various studies have provided converging evidence for the self-justification account of escalation effects (see Brockner, 1992, for a review). The typical self-justification finding is that commitment to an unfavorable course of action is increased when individuals feel personally responsible for initially choosing that course of action. Presumably, escalation of commitment is driven by the need to justify one's behavior (Brockner), and research

\footnotetext{
${ }^{2}$ Rubin et al. (1980) made a conceptual distinction between decision-making units that only involve one person versus multiple people. However they operationalized the social context as one that specifically involved a competition between people.
} 
has found this need to be greatest when individuals provide an explanation for why their chosen course of action is a good choice prior to receiving failure feedback about their course of action (Bobocel \& Meyer, 1994). In addition, self-justification tendencies tend to be more pronounced when important aspects of the self-concept are threatened. Such strong threats can occur, for instance, when individuals experience a discrepancy between their high competency beliefs (Stone, 2003) and the quality of the outcomes that are experienced from using their course of action. Moreover, Lieberman, Ochsner, Gilbert, and Schacter (2001) have demonstrated that self-justification processes may run off automatically, in that no explicit awareness of the aversive consequences from using one's course of action are necessary to trigger self-justification tendencies.

According to our perspective, individuals are particularly likely to face a difficult self-regulatory challenge as soon as negative consequences (i.e., negative performance feedback) are encountered regarding a chosen course of action. In such situations, people become trapped in a motivational conflict between the justification tendency and the desire for successful goal pursuit. Moreover, because people frequently rely on the intention to pursue the best course of action when performing a given task (Locke \& Latham, 1990), self-justification tendencies are likely to overpower them because, without a specification of when one will follow through on this good intention, such an intention is likely to be self-deceptive. Given that implementation intentions have been shown to be helpful with starting goal-directed action and continuing with a goal-directed action in the face of adversities, we hypothesized that implementation intentions would be effective in helping people perform an action that was necessary to resolve this conflict, namely disengagement from an unsuitable task means. In fact, given the recent work showing that implementation intentions aid people in overcoming automatic unwanted responses such as bad habits (see Gollwitzer et al., 2005), we were confident that implementation intentions could still effectively curb the tendency to hold on to a failing course of action regardless of whether escalation of commitment rests on implicit processes as implied by Lieberman et al. (2001).

As expected, results from our pilot study revealed that participants who supplemented their mere goal intention ("I will always pursue the best strategy!") with an implementation intention ("And if I receive disappointing feedback, then I'll switch to a different strategy!") were more successful than participants who relied solely on a mere goal intention or no intention at all in disengaging from an initial ineffective test taking strategy during a supposed general knowledge test. Moreover, results revealed that having the mere goal to always pursue the best test taking strategy did not increase disengagement rates as compared to control participants who did not rely on any self-regulatory intention. Importantly, follow-up questions revealed that the increase in disengagement achieved by implementation intentions was not due to increased dissatisfaction with the initial test-taking strategy, as there was no difference between the experimental groups in reported dissatisfaction.

\section{PRESENT RESEARCH}

The findings from the pilot study just described are important because they demonstrate the effectiveness of implementation intentions in reducing escalation effects. In addition, because the pilot study involved only a simple behavioral (quitting) response to a static failure experience, the findings also raise new and interesting questions regarding whether implementation intentions can increase sensitivity to dynamic changes (improvements or decrements) in performance that might occur prior to a failure experience. Given that previous research has shown that individuals who rely on implementation intentions delegate control of their actions to situational cues (Sheeran \& Orbell, 1999), one might assume that control of disengagement responses via implementation intentions would inevitably lead to costs in terms of rigidity or insensitivity to dynamic changes in task performance. In order to explicitly examine this issue, the present research compares an implementation intention that specifies a more complex reflection response ("If I receive disappointing feedback, then I'll think about how things have been going with my strategy!") to an implementation intention that specifies a more simple action response ("If I receive disappointing feedback, then I'll switch 
my strategy!"). Specifically, the present research investigates whether implementation intentions can inhibit disengagement after initial failure when a chosen course of action produces positive outcomes immediately prior to the failure feedback, while still further facilitating disengagement after initial failure when a chosen course of action produces negative outcomes immediately prior to failure feedback. It is critical to examine such an issue, particularly when dealing with escalation effects, because positive information about one's performance can serve as a signal that performance after initial failure is likely to improve, while negative information can serve as a signal that performance after initial failure is likely to continue to decline.

\section{STUDY 1: CAN IMPLEMENTATION INTENTIONS FACILITATE FLEXIBLE DISENGAGEMENT?}

In this study, we compared disengagement responses as a function of implementation intentions that specified either reflection in response to failure ("If I receive disappointing feedback, then I'll think about how things have been going with my strategy!") or action in response to failure ("If I receive disappointing feedback, then I'll switch my strategy!"). Based on the parallels between action implementation intentions and habitual S-R links produced by behavioral conditioning (Gollwitzer \& Sheeran, 2006), we suspected that an if-then plan that called for a simple behavioral response to a failure situation would allow for less flexibility in responding than a plan that called for a more complex cognitive response. Specifically, regardless of whether performance immediately prior to a failure experience signaled that an increase or decrease in the quality of performance was likely to follow the failure experience, we expected an action implementation intention would foster high rates of disengagement. In contrast, we expected a reflection implementation intention would leave people sensitive to changes in performance associated with a course of action. Therefore, we predicted that a reflection implementation intention would facilitate disengagement as a response to failure only when the failure experience was immediately preceded by a course of events (performance outcomes) signaling that a decrease in quality of performance was likely to continue. Finally, given that past implementation intention research has shown that self-regulation via mere goal intentions has only a moderate effect on goal attainment (i.e., reveals an intention-behavior gap, Gollwitzer \& Sheeran), we expected that regulation via a mere goal intention or no intention at all would lead people to escalate commitment. This latter outcome was thought to occur regardless of whether performance prior to the failure feedback signaled that an increase or decrease in quality of performance was likely to follow a failure experience (see Figure 1 for an illustration of the predicted results).

In this study, we invited participants to take part in a supposed general knowledge test. Participants were given the opportunity to choose a particular course of action (i.e., a certain test-taking strategy) in order to reach their goal of doing well on a general knowledge test. After choosing their strategy, all participants justified why they chose their particular strategy. This procedure has been shown to effectively induce escalation effects (Bobocel \& Meyer, 1994). Before starting the test, some participants were asked to form the goal intention of only working with the best strategy during the test; the remaining participants started the test immediately. Half of those participants who formed a goal intention were asked to form either an additional action implementation intention or a reflection implementation intention, both of which specified how to work with the best strategy. While working on the test, participants received failure feedback regarding their performance on the test, and were given the opportunity to change their strategy after receiving this feedback.

\section{METHOD}

\section{Participants and design}

Participants were 183 native German-speaking participants (105 men, 78 women) at the University of Hamburg, who participated for 8 Euro (5 US dollars). No sex differences emerged for any of the analyses 


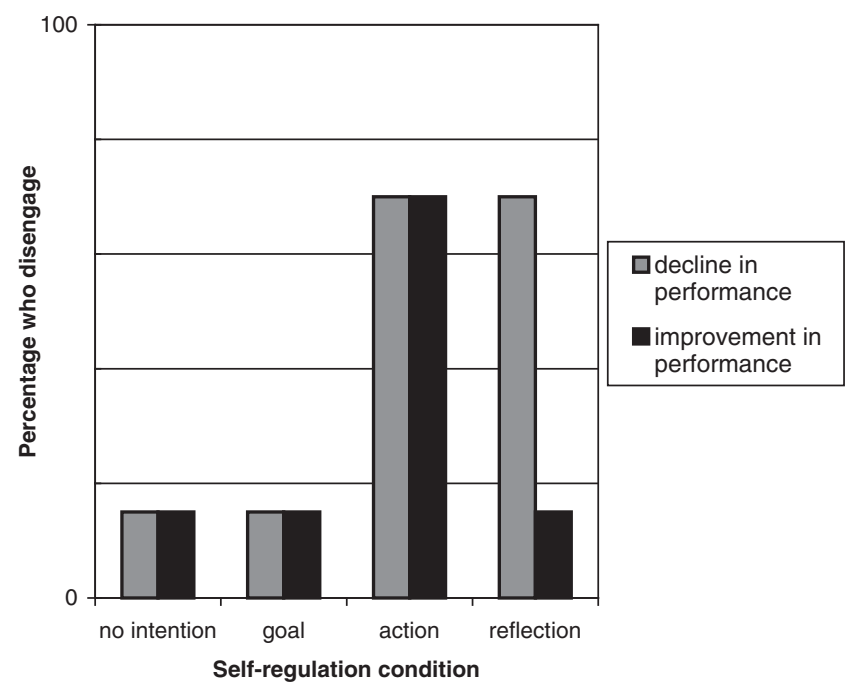

Figure 1. Predicted pattern of disengagement after performance decline versus performance improvement as a function of type of self-regulation (study 1)

reported. The study used a 4 (self-regulation condition: goal intention, action implementation intention, reflection implementation intention, no intention control) $\times 2$ (preceding performance: improvement vs. decline) between-factors design.

\section{Procedure and materials}

Escalation of commitment paradigm

We modified the paradigm of Bobocel and Meyer (1994) and told participants that the purpose of the study was to investigate the different levels of people's general knowledge. Participants were informed that they would be required to work on a supposed general knowledge test that consisted of items adapted from German trivia games. Participants were told that they must correctly answer items that the majority of past participants had answered incorrectly. Emphasis was placed on answering items that the majority had answered incorrectly in order to bolster the believability of any negative feedback that was delivered during the task. Even if participants believed that they answered items correctly, any negative feedback was made believable in our task because participants had no way of knowing how the majority of past participants had performed. They were instructed to strive to maximize their points on the test and that they should focus on the goal of doing well on the test. As noted by Bobocel and Meyer, previous research indicates that such instructions are effective in eliciting a strong achievement orientation in the laboratory (e.g., Sorrentino, 1973).

Participants were given the option of selecting one of three performance strategies (see Performance strategies below) that varied the number of items that were presented on each screen and the supposed number of points that were earned and deducted for correct and incorrect responses. After being presented with a description of the potential merits and drawbacks of each strategy option, participants chose one strategy and provided a justification for their choice. After participants justified their choice of strategy, they were presented with a self-regulatory thought that involved the self-regulation manipulation (see Self-regulation conditions below). Participants in the goal intention and goal intention plus implementation 
intention conditions responded to a goal commitment check (see Goal commitment below). All participants then started the test.

\section{Performance strategies}

For all three strategies, participants were required to respond to 20 screens of general knowledge items and were given the opportunity to supposedly gain a maximum of 3 points and lose a maximum of 3 points from the item(s) presented on each screen. Participants were informed that all test items that were presented on each screen would remain on the screen for 20 seconds. The one-item strategy presented one item on each screen and three points were earned for correctly answering items that the majority had answered incorrectly, zero points were earned for correctly answering items that the majority had answered correctly, and three points were deducted for incorrectly answering items. The two-item strategy was similar to the one-item strategy except that two items were presented on each screen and 1.5 points were earned and deducted for each item instead of three points. The three-item strategy was similar to the one-item strategy except that three items were presented on each screen and one point was earned and deducted for each item instead of three points. For all three strategies, participants were not allowed to skip items.

After presenting participants with a description of the strategies, we then presented them with a description of the potential pros and cons associated with each strategy. Participants were told that the fewer items that were presented on the screen, the greater were their chances of gaining points by having more time to consider the correct answer for each item. They were also told that the more items that were presented on the screen, the greater were their chances of gaining points by having more opportunities to encounter items that they knew the answer to. Also, by having more items on the screen, less value or weight was placed on getting all of the items correct on each screen. Participants were then told that the one-item strategy might hinder performance if the item on a particular screen was too difficult, while the three-item strategy might hinder performance if the items required too much time. In essence, participants were told that the one-item strategy might lead to better performance by increasing the quality of their responses, whereas the three-item strategy might lead to better performance by increasing the quantity of their responses. We provided a description of the potential benefits and drawbacks of each strategy in order to convince participants that their strategy choice would have an impact on the quality of their performance. Unbeknownst to the participants, however, the strategies had no impact on their performance.

After participants had chosen their strategy, they were required to justify why they had chosen their particular strategy by providing a written explanation to the experimenter about why their chosen strategy worked best for them. This procedure was designed to mirror the public-justification condition of the Bobocel and Meyer (1994) experiment. To create a critical test of the power of implementation intentions in helping people to disengage, we needed to create a situation in which all participants would initially be unwilling to disengage from a failing course of action. Bobocel and Meyer's public justification condition is known to produce a strong escalation of commitment effect (i.e., low disengagement rates) following failure, and thus, we adapted this procedure for all of our participants.

\section{Self-regulation conditions}

The experimental manipulation of self-regulatory thought was presented on the computer to participants after they justified their choice of strategy. Specifically, participants in the goal intention and goal intention plus implementation intention conditions encountered a screen with the following statement, "On the next screen, you will be shown a mental exercise that you should engage in before starting the test. You will have approximately 10 seconds. After 10 seconds, a Next button will appear." Participants were not given any specific rationale or cover story about why they were presented with the self-regulatory thought. Participants in the goal intention condition repeated the statement "I will only work with the best strategy!" to 
themselves. Participants in the action implementation intention condition repeated the above goal intention to themselves along with the statement "If I receive disappointing feedback, then I'll switch my strategy!" Participants in the reflection implementation intention condition repeated the relevant goal intention to themselves along with the statement "If I receive disappointing feedback, then I'll think about how things have been going with my strategy!" Participants in the control condition were not asked to repeat to themselves any self-regulation statements.

\section{Goal commitment}

Before starting the general knowledge test, the perceived importance of the goal intention was checked by means of the following item: "How important is it for you to work with the best strategy during this test?" The answer scale ranged from not at all important (1) to very important (7). Given that participants in the control condition were not assigned a disengagement goal, control participants did not respond to this item.

\section{Improvement or decline in performance}

Participants in this study received immediate (false) information about their performance on each test screen. For each of the first 10 screens, immediately after participants completed the item(s) on each screen, they were given information indicating either success or lack of success. Specifically, 50\% of the time after the participant responded to the item(s) on the screen, the words "points gained" appeared in the bottom left hand corner of the screen, indicating points had been scored from that screen's item(s). The remaining 50\% of the time, nothing appeared in the bottom left hand corner indicating that points had been deducted or zero points had been gained.

After participants responded to 10 computer screens of items, over which they were told that they were successful $50 \%$ of the time, they were interrupted and told the following:

You have just completed the first part of the test. Your performance up to this point will be calculated and you will receive a feedback report of how well you are doing compared to previous participants. Because this feedback process involves a comparison of your performance with our entire database, it takes a few minutes to complete it. We apologize for the delay. Press the "Calculate Feedback" button to begin the process and continue with the test. When your feedback report is ready, you will automatically be notified that it is ready. Note that your performance from this point on will not be included in this feedback report. It will be included in your next feedback report.

Following this interruption, participants were assigned to either the improvement in performance condition or the decline in performance condition and then continued responding to 10 additional screens (i.e., screens 11-20) of general knowledge statements. Participants assigned to the improvement condition were shown "points gained" on nine of these screens, whereas participants assigned to the decline condition were shown "points gained" on only one of these screens. After this manipulation, all participants were interrupted again and told that their feedback report from the first part of the test (i.e., screens 1-10) was ready to be viewed. This feedback report presented the failure feedback for the first part of the test (see Failure feedback section below).

\section{Failure feedback}

Once participants had responded to screens 11-20 of general knowledge items, they were interrupted and given feedback regarding their performance on screens 1-10. Specifically, they were told:

Your feedback report regarding your performance on the first part of the test is now ready. Press the "Get Feedback" button to retrieve your feedback report. 
Next, participants were told that they had performed at approximately the "65th percentile" on the first part of the test (i.e., screens 1-10), and were shown the following reference guide:

95th percentile or higher $=$ excellent performance.

90th percentile $=$ very good performance.

80th percentile $=$ good performance.

70th percentile $=$ moderate performance.

60th percentile or lower $=$ poor performance.

\section{Dependent measure}

Next to the feedback report, participants were presented with the option of either changing or maintaining their current strategy. Specifically, participants were presented with one button labeled "continue with test" and another button labeled "change my strategy." Whether participants chose to remain with their initial strategy served as our measure of disengagement. After completing the measure, participants were thanked and thoroughly debriefed about the false failure feedback, the false nature of the performance strategies, and the purpose of the present study.

\section{RESULTS}

\section{Goal commitment}

An analysis of variance (ANOVA) conducted on participants' rating of how important it was for them to only work with the best strategy found no significant differences $(F<1)$ between conditions. Participants in the goal intention $(M=4.91)$, action implementation intention $(M=4.74)$, and reflection implementation intention $(M=4.85)$ groups were equally concerned with using only the best strategy throughout the test.

\section{Disengagement from chosen strategy}

We analyzed the data using logistic regression (cf. Lottes, DeMaris, \& Adler, 1996). First, in order to examine the effects of self-regulating with different types of intentions on participants' decision to disengage from their chosen strategy, we conducted a logistic regression on participants' decision to switch their strategy. We treated participants in the no intention control group as the reference group, and examined the effects of adopting a mere goal intention, of adopting an action implementation intention, and of adopting a reflection implementation intention. As we expected the effect of adopting a reflection implementation intention on participants' disengagement decision to vary as a function of the type of performance that preceded failure, we also examined the interaction effect of experiencing an improvement in preceding performance and of adopting a reflection implementation intention (see Table 1). Our results showed nearly equal ODDS of switching strategies for participants in the goal intention and no intention control groups. Results also showed that the ODDS of switching for participants in the action implementation intention group were over two times higher than the ODDS for participants in the no intention control group. As expected, the results further showed that the effect of a reflection implementation intention on participants' decision to switch their strategy depended on the type of performance that preceded the perceived failure. Specifically, results revealed that only when participants experienced a decline in performance were the ODDS of switching strategies for participants in the reflection implementation intention group higher than the ODDS for participants in the no intention control group (see Table 2).

Next, we conducted separate logistic regression analyses for each condition in order to fully examine which self-regulatory conditions were affected by the performance information that preceded failure. We 
Table 1. Coefficient statistics from logistic regression (study 1)

\begin{tabular}{lcccc}
\hline Variable & $b$ & S.E. & Odds ratio & $p$-value \\
\hline Constant & -0.51 & 0.35 & 0.60 & 0.15 \\
$\quad$ Self-regulation condition & & & & \\
$\quad$ Goal intention & 0.10 & 0.44 & 1.10 & 0.83 \\
$\quad \begin{array}{l}\text { Action implementation intention } \\
\quad \text { Reflection implementation intention }\end{array}$ & 0.90 & 0.43 & 2.45 & 0.04 \\
$\quad \begin{array}{l}\text { Preceding performance } \\
\quad \text { Improvement }\end{array}$ & -0.17 & 0.58 & 3.82 & 0.02 \\
$\quad \begin{array}{l}\text { Preceding performance interaction with } \\
\quad \text { Reflection implementation intention }\end{array}$ & -1.29 & 0.35 & 0.85 & 0.64 \\
\hline
\end{tabular}

Table 2. Percentage of participants disengaging after performance decline versus performance improvement as a function of type of self-regulation (study 1)

\begin{tabular}{lcccc}
\hline & & Self-regulation condition & \\
\cline { 2 - 5 } $\begin{array}{l}\text { Preceding } \\
\text { performance } \\
\text { condition }\end{array}$ & $\begin{array}{c}\text { No intention } \\
\text { control }\end{array}$ & $\begin{array}{c}\text { Goal } \\
\text { intention }\end{array}$ & $\begin{array}{c}\text { Action implementation } \\
\text { intention }\end{array}$ & $\begin{array}{c}\text { Reflection implementation } \\
\text { intention }\end{array}$ \\
\hline $\begin{array}{l}\text { Decline } \\
\text { Improvement }\end{array}$ & $39 \%(23)$ & $39 \%(23)$ & $58 \%(23)$ & $70 \%(24)$ \\
\hline
\end{tabular}

Note: Total number of participants in each condition are in the parentheses.

treated the decline in preceding performance as the reference group, and examined the effect of experiencing an improvement in performance prior to failure on participants' decision to switch their strategy. Only for participants in the reflection implementation intention group did an improvement in performance affect their ODDS of switching strategies, $\mathrm{B}=-1.46$, Odds Ratio $=0.23, p=0.02$. For participants in the no intention control, goal intention, and action implementation intention groups, an improvement in performance had no impact on their ODDS of switching strategies, $\mathrm{B}=-0.32$, Odds Ratio $=0.73, p=0.61, \mathrm{~B}=-0.12$, Odds Ratio $=0.89, p=0.85$, and $\mathrm{B}=-0.07$, Odds Ratio $=0.93, p=0.90$, respectively (see Table 2 ).

\section{DISCUSSION}

An action implementation intention produced a high rate of disengagement regardless of whether the specified cue (i.e., failure feedback) was preceded by a purported improvement or decline in performance on the general knowledge test. No matter whether things looked for the better or worse, action implementation intention participants were ready to change their strategy after failure feedback. Such a lack of sensitivity to subsequent performance is completely consistent with implementation intention theory, as simple behavioral responses ("switch") that are specified in the then-part of an implementation intention are posited to occur in an automatic fashion once the critical cue ("failure") specified in the if-part is encountered. Interestingly, the low disengagement rates observed for the control and the goal intention groups also remained unaffected by participants' subsequent performance. However, unlike action implementation intention participants, when things looked for the better or worse, control and goal intention participants preferred to stay with their chosen strategy after failure feedback. Such a lack of sensitivity to subsequent performance seems to be 
completely consistent with prior work on escalation of commitment, as individuals who choose a chosen course of action have been shown to remain fully committed to that course of action despite the negative consequences that follow. As expected, our findings demonstrated that it was only the reflective implementation intention participants who adjusted their disengagement rates as a function of experiencing a spurt or collapse in performance prior to failure feedback. When performance showed signs of improvement, disengagement was low; however, when performance continued to show signs of a decline, disengagement was high.

This study was informative in several ways. First, it confirmed that supplementing disengagement goals with implementation intentions is an effective means for combating escalation of commitment. Second, it confirmed that the benefits of implementation intentions in disengagement contexts is not limited to if-then plans that call for a simple behavioral response, as a reflection implementation intention that called for a more complex assessment of the course of action also reduced escalation. Third, it appears then that the self-regulatory strategy of forming implementation intentions does not have to lead to rigid disengagement decisions. It all depends on what kind of "then" is linked to the "if" (i.e., receiving disappointing feedback) of the implementation intention. If the then-part specifies a reflective assessment response, flexible disengagement occurs which takes into account further reasons to disengage or not (e.g., recent developments in performance). If the then-part specifies a behavioral switching response, disappointing failure feedback determines disengagement no matter whether mitigating circumstances are present or not. Lastly, the present pattern of data also highlights that mere goal intentions (e.g., to always use the best test strategy) do not seem to achieve the same type of reflectivity as an implementation intention that specifies assessment in response to a critical stimulus (e.g., failure). It takes the extra effort in terms of adopting a reflection implementation intention to achieve reflective goal pursuit.

It is important to note that the results from this study showed that when failure was encountered after a continual decline in performance, both a reflection and an action implementation intention led to similar high rates of disengagement. By observing similar rates of disengagement in a situation where failure appeared to be mounting, this study leaves unanswered the question of when is it better to adopt a particular type of if-then plan in such a situation. In this study, disengagement decisions were made under conditions that were relatively calm and distraction free. In Study 2, we examine whether implementation intentions that specify action versus reflection work best under conditions of high arousal.

Often times, individuals deal with multiple factors that produce high amounts of frustration and arousal, such as time pressure, during the decision-making process (Luce, Bettman, \& Payne, 1997; Payne, Bettman, \& Johnson, 1988). Of course, in a disengagement context, such factors should matter little when simple self-regulatory responses are specified in the then-part of an implementation intention. Indeed, according to classic learning theories of Hull (1943) and Spence (1956), increased arousal should enhance the emission of dominant responses by increasing an individual's level of general drive, which with simple self-regulatory tasks should entail a greater likelihood of executing the appropriate self-regulatory response. With complex self-regulatory tasks, however, the dominant response involves a failure to execute the appropriate self-regulatory response, and as a result, increased arousal should entail a lesser likelihood of executing the appropriate self-regulatory response. Drawing on such learning theories, we hypothesized that conditions of high arousal would make it easier to successfully execute a simple disengagement response on the one hand, but make it more difficult to successfully execute a complex disengagement response on the other hand (Hull; Spence; see also Amsel, 1994; Amsel \& Maltzman, 1950; Amsel \& Ward, 1954).

\section{STUDY 2A: DOES TIME PRESSURE INCREASE AROUSAL?}

For the current study, we operationalized a state of high arousal by placing individuals under time pressure while making self-regulatory decisions. To first establish that making a decision under increased time 
pressure does indeed lead to high levels of arousal, a preliminary study was conducted in which participants (10 men, 21 women) answered demographic questions under high versus low time pressure. Sixteen participants were in the high time pressure condition and 15 participants were in the low time pressure condition. After answering the demographic questions, participants indicated the extent to which they felt different forms of affect related to arousal and different forms of affect unrelated to arousal.

Participants in the high time pressure condition were told that the study was concerned with how people make decisions in situations in which decisions need to be made quickly. Participants then answered some demographic questions, including questions that asked them to identify their gender, age, education level, mode of travel (bus, train, taxi) that they most often use to travel to work or school, and the mode of travel that they most often use to engage in leisure activities. While responding to each question, a small clock was displayed on the screen and participants were given 5.5(seconds) to type in their response to each question. Participants in the low time pressure condition answered the same demographic questions without the mention of a time constraint. Next, we measured the extent to which participants in both conditions felt aroused, energized, stressed, happy, hostile, strong, and interested by means of the following seven-point rating scale: "When you were answering the main questions on the previous page, how did you feel?"

The answered scaled ranged from (1) not at all to (7) very. The first three affective terms were chosen because they were expected to be more sensitive to the amount of arousal experienced by participants, whereas the last four terms were chosen to rule-out the possibility that time pressure produces more affect in general. Finally, we measured how much time pressure participants felt while answering the demographic questions by means of the following seven-point rating scale: "How much time pressure did you feel when you were answering the main questions on the previous screens?" The answer scale ranged from (1) minimum time pressure to (7) maximum time pressure.

Results showed that compared to participants in the low time pressure condition, participants in the high time pressure condition were more aroused, $M=1.67$ versus $M=4.38, t(29)=5.19, p<0.001, d=1.93$, energized, $M=3.27$ versus $M=5.25, t(29)=4.48, p<0.001, d=1.66$, and stressed, $M=1.93$ versus $M=4.31, t(29)=4.13, p<0.001, d=1.53$. Participants in the low and high time pressure conditions did not differ in their reported hostility, $M=1.33$ versus $M=2.13, t(29)=1.69, p=0.10$, happiness, $M=3.53$ versus $M=3.44, t<1$, strength, $M=3.47$ versus $M=3.19, t<1$, or interest, $M=3.13$ versus $M=3.75$, $t(29)=1.00, p=0.32$. Participants in the high time pressure condition reported feeling greater time pressure, $M=5.06$, than participants in the low-time pressure condition, $M=2.07, t(29)=4.90, p<0.001, d=1.82$. Therefore, we felt confident in operationalizing low and high arousal in the next study by manipulating low and high time pressure during decision making.

\section{STUDY 2B: DOES AROSUAL MODERATE THE EFFECT OF IMPLEMENTATION INTENTIONS ON DISENGAGEMENT?}

Several studies conducted within the framework of classic learning theories (Hull, 1943; Spence, 1956; see also Thibaut \& Kelley, 1959; Zajonc, 1965) support the notion that the execution of complex responses suffers from states of high arousal while the execution of simple responses benefits from states of high arousal (e.g., Katahn \& Koplin, 1966; Katahn \& Lyda, 1966; Spence, Taylor, \& Ketchel, 1956). While implementation intention theory posits that the instigation of responses occurs automatically as a function of forming if-then plans, it remains an open question as to whether the successful execution of responses is dependent on other factors such as arousal. We argue that the disengagement response specified by an action implementation intention represents a relatively simple response, whereas the disengagement response specified by a reflection implementation intention represents a more complex response. Consequently, we tested whether, given conditions of high arousal, a simple action implementation intention as well as a 
complex reflection implementation intention would evidence more or less effective disengagement when failure was encountered after a continual decline in performance.

In this study, we invited participants to take part in a role-playing exercise that involved adopting the role of a person who lives in one city but commutes to work in a different city. Participants were asked to imagine themselves as an employee who had recently started a new job. They were exposed to information about the possible ways that they as the employee might choose to get to work. After reading over this information, they were asked to pick a way that they would choose to get to work in order to arrive on time to work in the cheapest way possible. After choosing their mode of travel, all participants justified why they chose their particular mode of travel. Before starting the exercise, all participants were asked to form the goal intention of only using the best mode of travel. Half of the participants were asked to form either an additional action implementation intention or a reflection implementation intention, both of which specified how to use the best mode of travel. While going through the exercise, participants received failure feedback regarding their promptness at work with their chosen mode of travel. After receiving this failure feedback, all participants reported their likelihood of continuing with their mode of travel. Half of the participants, however, were placed under high time pressure while making their decision, while the other half was placed under low time pressure while making their decision.

As the specified response in an action implementation intention is the mere act of switching, the execution of this simple response should benefit from increased arousal produced by time pressure. However, as the specified response in a reflection implementation intention is a complex thought process that takes into account one's history of failure, executing this response should not benefit from time pressure.

\section{METHOD}

\section{Participants and design}

Participants were 48 native English-speaking participants (20 men, 31 women) at New York University, who participated for 10 dollars. No sex differences emerged for any of the analyses reported. The study used a 2 (self-regulation condition: action implementation intention vs. reflection implementation intention) $\times 2$ (time pressure: low vs. high) factorial design. There were 12 participants in each condition.

\section{Procedure and materials}

\section{Escalation of commitment paradigm}

Participants were asked to engage in a hypothetical role-playing exercise that involved an employee who committed to a particular course of action (mode of travel) to arrive on time to work each day. Such role-playing exercises have been used in previous escalation of commitment research (e.g., Arkes \& Blumer, 1985; Conlon \& Garland, 1993; Garland, 1990; Moon, 2001a). All participants were told that the purpose of the study was to investigate how people make decisions in work environments. Participants were asked to imagine that because the rent in the city is so expensive, they live in a smaller town outside of the city. They then learned that their apartment was far away and that it costs them a lot of time and money to commute to work. Afterwards, participants were asked to imagine that their boss had agreed to pay half of their commuting costs. However, in order to receive the assistance, they were told that they must justify their chosen mode of travel. Specifically, participants read a short description that explained the company's reimbursement policy. Participants were then given the option of selecting one of three modes of travel (see Travel modes below). After being presented with a description of the potential merits and drawbacks of each mode of travel, participants chose one mode of travel and provided a justification for their choice. After participants justified their choice of travel mode, they were presented with a self-regulatory thought that 
involved the self-regulation manipulation (see Self-regulation conditions below). All participants then proceeded with the exercise.

\section{Travel modes}

Participants were presented with the following three ways that they could choose to get to work:

If you take Mode A to get to work, you would have to walk to a bus stop, take the bus to the main bus station, and then walk from the bus station to work. Of all the modes, this one is the cheapest. In addition, the bus stop is really close to your home and the bus station is really close to your work, which is a perk when it is really cold outside. Unfortunately, the bus tends to be unreliable, so sometimes it comes really early, but other times it comes really late.

If you take Mode $B$ to get to work, you would have to walk to a train stop, take the train to the main train station, and then walk from the train station to work. Of all the modes, this one is the most reliable, and the price is in between Mode A and C. However, the train stop is somewhat farther away from your home than the bus stop, and the train station is somewhat farther away from your work than the bus station. Also, although the train always arrives at your particular train stop on time, it is sometimes late arriving at the main train station because it sometimes has to stop on the way to the main train station when cars are crossing its tracks.

If you take Mode $C$ to get to work, you would have to call a car service to come pick you up and take the car all the way to work. Of all the modes, this one is the most comfortable, and you never have to worry about walking to work. But the price is the most expensive of all the modes of travel. Also, traffic tends to be congested in the morning, so the time it takes to get to work can vary greatly.

We provided a description of the potential benefits and drawbacks of each mode of travel in order to help participants imagine that their mode of travel choice would have an impact on the quality of their promptness at work. After participants had chosen their mode of travel, they were required to provide a justification to the boss about why their mode of travel would be the best mode for them to take to work. As in Study 1, this procedure was designed to mirror the public-justification condition of the Bobocel and Meyer (1994) experiment.

\section{Self-regulation conditions}

The experimental manipulation of self-regulatory thought was presented on the computer to participants after they justified their choice of travel mode. Specifically, all participants encountered a screen that read "Now imagine that on the first day that you start using your chosen mode of travel, the following thought occurs to you: I will only use the best mode of travel." Participants in the action implementation intention condition read the above goal intention along with the statement "If I get disappointing feedback about my promptness at work, then I'll switch my mode of travel!" Participants in the reflection implementation intention condition read the relevant goal intention with the statement "If I get disappointing feedback about my promptness at work, then I'll think about how things have been going with my mode of travel!"

\section{Failure feedback}

After being exposed to the self-regulatory thought, participants read information about their supposed promptness to work using their mode of travel. Specifically, participants encountered several screens, each with a button on it labeled "tell me what happened the next day." After clicking the button, each screen gave 
information about their attendance at work for that particular day. For each of the first 10 screens, participants were given information indicating their success and lack of success at arriving on time to work. On 50\% of the days, the statement "you arrive late to work" appeared at the top left hand corner of the screen. The remaining 50\% of the days, the statement "you arrive on time to work" appeared at the top left hand corner of the screen. After participants learned about their promptness to work, over which they were told that they were successful at arriving on time to work $50 \%$ of the time, they were interrupted and told the following:

After traveling to work for the first part of the month, you learn that your company will soon be releasing its annual attendance report for all of its employees. Because you just started working at the company, your annual attendance report will only be based on the first part of the month that you have been on the job. You learn that it takes some time to prepare the attendance reports and that your company will notify each employee when their attendance report is ready. Thus, regardless of when you receive it, your first attendance report will only be based on the first part of the month. Work attendance from this point on will only affect your next annual attendance report.

After receiving this interruption, participants experienced a decline in their promptness to work as they continued through 10 additional days of commuting to work (i.e., screens 11 to 20). Specifically, participants were shown "you arrived late to work" on 7 out of the 10 screens. Afterwards, participants were interrupted again and told their attendance report regarding the first part of the month (i.e., screens 1 to 10) was ready to be viewed. This attendance report presented failure feedback regarding the first part of the month that participants imagined commuting to work. That is, after participants had gone through screens 11 to 20 regarding their commute to work, they were specifically told to imagine that their boss told them "Although you're not the tardiest employee we have on record, your promptness at work needs improvement. Compared to the average lateness of all employees, your promptness at work is somewhat poor."

\section{Time pressure condition}

Participants in the high time pressure condition were told that the study was concerned with how people make decisions in a work environment under circumstances in which decisions need to be made very quickly. After reading the attendance report, participants were asked to respond to the dependent measure as quickly as possible (see Dependent measure section below). Specifically, participants were given 5.5(seconds) to answer the dependent measure. In order to indicate how much time was left as they answered each question, a small timer appeared underneath each question. As 5.5(seconds) passed, the clock slowly disappeared. If participants were unable to answer the question, it reappeared shortly thereafter, giving participants another 5.5(seconds) to answer the question. If participants were still unable to answer the question, no response was recorded for the question. For participants in the low time pressure condition, no mention of a time constraint during decision-making was made, and no time limit was given for responses to the dependent measure.

\section{Dependent measure}

We measured participants' likelihood of disengaging from their chosen mode of travel by means of the following seven-point scale: "How unlikely/likely would you be to continue using your chosen mode of travel? (reverse coded). The answer scale ranged from (1) very unlikely to (7) very likely. Participants in the high time pressure condition responded to this question under time pressure, while participants in the low time pressure condition were allowed to take as much time as they wished to make their decision. Afterwards, we measured how much time pressure participants felt while making their self-regulatory response by means of the following seven-point rating scale: "How much time pressure did you feel when you were answering 
the main question on the previous screen?" The answer scale ranged from (1) minimum time pressure to (7) maximum time pressure. We also measured perceived experimenter demand by means of the following seven-point rating scale: "When you were answering the main question on the previous screen, did you suspect that whoever designed this questionnaire wanted you to change your chosen mode of travel?" The answer scale ranged from (1) definitely no to (7) definitely yes.

\section{RESULTS}

\section{Felt time pressure}

Participants' ratings of how much time pressure they felt while reporting their likelihood of changing their chosen mode of travel was analyzed using a 2 (Self-regulation condition: action implementation intention vs. reflection implementation intention) $\times 2$ (time pressure: low vs. high) ANOVA. As expected, there was a main effect for time pressure, $F(1,47)=52.25, p<0.001$, with participants in the high time pressure condition reporting more time pressure $(M=5.44)$ than participants in the low time pressure condition $(M=2.50)$. We found no main effect of self-regulation condition, $F<1$, and no self-regulation $\times$ time pressure interaction effect, $F<1$.

\section{Likelihood of disengaging}

Participants' self-reported likelihood of changing their chosen mode of travel was analyzed using a 2 (self-regulation condition: action implementation intention vs. reflection implementation intention) $\times 2$ (time pressure condition: low vs. high) ANOVA. There was no main effect of time pressure condition, $F(1$, $44)=2.75, p=0.11$. Results did reveal a main effect of self-regulation condition, $F(1,44)=6.18, p<0.05$, which was qualified by an interaction with the time pressure condition, $F(1,44)=7.03, p<0.05$ (see Table 3).

We analyzed the simple effect of time pressure on action implementation intention participants' reported likelihood of changing their chosen mode of travel. Consistent with our hypotheses, results showed that participants in the high time pressure condition reported a greater likelihood of changing their mode of travel than participants in the low time pressure condition, $M=6.67$ versus $M=4.50, t(22)=3.07, p<0.01$, $d=1.31$. Next, we analyzed the simple effect of time pressure on reflection implementation intention participants' reported likelihood of changing their chosen mode of travel. Although the pattern of results suggest that participants in the high as opposed to the low time pressure condition exhibited a lower likelihood of changing their mode of travel, $M=4.08$ versus $M=4.58$, this difference was not significant, $t<1$.

We also analyzed the simple effect of the self-regulation manipulation on high time pressure participants' reported likelihood of changing their chosen mode of travel. As expected, participants in the action

Table 3. Ratings of participants' reported likelihood of changing their course of action when time pressure was absent versus present as a function of type of self-regulation (study 2)

\begin{tabular}{lccccc}
\hline & \multicolumn{2}{c}{ Self-regulation condition } \\
\cline { 2 - 3 } & \multicolumn{2}{c}{ Action implementation intention } & & \multicolumn{2}{c}{ Reflection implementation intention } \\
\cline { 2 - 3 } & No time pressure & Time pressure & & No time pressure & Time pressure \\
\hline Disengagement likelihood & $4.50(2.07)$ & $6.67(1.30)$ & & $4.58(1.88)$ & $4.08(1.62)$ \\
\hline
\end{tabular}

Note: Standard deviations are in the parentheses. 
implementation intention condition reported a greater likelihood of changing their mode of travel than participants in the reflection implementation intention condition, $t(22)=4.30, p<0.001, d=1.83$. We also analyzed the simple effect of the self-regulation manipulation on low time pressure participants' reported likelihood of changing their chosen mode of travel. Specific comparisons revealed no difference between participants in the action implementation intention and reflection implementation intention conditions in their likelihood of changing their mode of travel, $t<1$.

\section{Experimenter demand}

Participants' ratings of perceived experimenter demand were entered into a 2 (self-regulation condition: action implementation intention vs. reflection implementation intention) $\times 2$ (time pressure condition: low vs. high) ANOVA. Neither the main effect of self-regulation condition $(F<1)$, the main effect of time pressure $(F<1)$, nor the interaction effect $(F<1)$ reached significance. With regards to our experimental manipulation, participants in the action implementation intention group $(M=3.85)$ and reflection implementation intention group $(M=4.28)$ did not differ in the extent to which they felt experimenter pressure to disengage from their chosen course of action. Moreover, the results reported in the previous paragraphs remained unchanged after controlling for perceived experimenter demand. Based on these results, an alternative explanation of the observed results in terms of experimenter demand does not seem tenable.

\section{DISCUSSION}

The current study suggests that when time pressure is low during decision-making, both action and reflection implementation intention participants are equally likely to disengage after a continual decline in performance. When individuals are forced to make their self-regulatory decisions under high time pressure, however, only action implementation intention participants evidence a higher likelihood of disengaging in response to continued failure. That is, under high arousal the simple planned response benefits, but the complex planned response does not.

The findings from this study are informative for the following reasons. First, they provide a conceptual replication of the findings from Study 1. If-then plans that called for either a simple behavioral change or a complex reflective assessment in response to failure led individuals to respond in a similar fashion (under low time pressure) when failure was encountered after a decline in performance. Second, it identified a specific moderator of the effects of implementation intentions in disengagement contexts, namely time pressure, and suggests that arousal in general may have more of a positive impact on implementation intentions that specify simple reflexive responses.

\section{GENERAL DISCUSSION}

The results of the present set of studies indicate that implementation intentions can serve as an effective self-regulatory strategy for combating escalation effects. While our studies suggest that disengagement via action implementation intentions will occur in an automatic, context-independent manner, our findings regarding reflection implementation intentions indicate that mindful disengagement via if-then planning is

also possible. In Study 1, we found that an implementation intention that specified reflective thought rather than decisive action in its then-part allowed for sensitivity to information relevant to disengagement other than failure feedback. Specifically, participants who planned to assess their chosen course of action respected 
additional information (in this case improvement in performance prior to the failure feedback) in their disengagement decisions, whereas participants who planned to alter their chosen course of action and participants who simply intended to pursue the best course of action failed to do so. Participants with a reflection implementation intention maintained goal pursuit in the face of failure feedback when they received a sign (i.e., recent improvements in performance) that the chosen strategy might not be that bad after all. Therefore, having formed a reflection implementation intention seems more valuable in situations where any such signs hint at what will happen in the future (Oettingen \& Thorpe, 2005). If these signs do not correctly indicate what will happen in the future, however, having formed an action implementation intention seems like the better self-regulation solution as this implementation intention fostered high rates of disengagement regardless of the circumstances surrounding failure.

In Study 2, we found that an implementation intention that specified decisive action rather than reflective thought in its then-part facilitated a greater likelihood of disengagement when individuals were in a state of high rather than low arousal during decision-making. Specifically, after failure was encountered, participants who planned to alter their chosen course of action in response to failure evidenced a higher likelihood of changing their course of action when time pressure was present rather than absent during decision-making. Participants who planned to reassess their chosen course of action in response to failure, on the other hand, failed to show any benefit or enhanced disengagement under high time pressure. Across the current set of studies, the observed differences between implementation intentions that specify acting and implementation intentions that specify reflective thought suggest that participants who self-regulate with an action implementation intention ready themselves for spontaneous action without deliberation. Such a lack of deliberation in the latter case is consistent with research demonstrating the efficiency of self-regulation by implementation intentions (Brandstätter et al., 2001). Indeed, forming an action implementation intention seems more valuable in situations where factors that might distract or frustrate the individual are likely to be encountered.

\section{Multiple antecedents of escalation}

While the current set of studies only focused on one potential source of escalation (i.e., the justification motive), we recognize that researchers have also studied other determinants of escalation effects. Proponents of prospect theory (e.g., Whyte, 1986), for example, have argued that loss aversion seduces individuals to stick with an unproductive course of action. As Brockner (1992, pp. 50-51) put it:

As more and more resources are allocated to the failing course of action, decision makers have two options: either they can cut their losses or they can continue to commit themselves to the previous course of action... Given loss aversion, and given the context value function in the domain of losses, individuals will be risk seeking (i.e., they will prefer to allocate additional resources in the hope of turning the situation around, rather than to accept the sure loss if they were to stop allocating resources at that point).

According to the prospect theory account, a decision made after receiving negative feedback is construed as a choice between losses, which in turn results in risk seeking. In a loss frame, people are inclined to take risks and thus stay with a strategy that will probably not pay off (Whyte, 1986).

Recently, project completion effects have been put forth as an explanation for why people escalate their commitment to a failing course of action. Presumably, as an individual progresses through a task, concerns that were initially prominent when performance on the task was started become less of a priority as the individual becomes increasingly more concerned about completing the task with their current course of action (Garland \& Conlon, 1998; Moon, 2001a). Rather than a consequence of self-justification, a kind of Zeigarnik tendency is thought to occur that makes people stick with their chosen course of action to avoid the tension that exists when a course of action on a task is left unfinished (Zeigarnik, 1927). 
A review of the extant literature on how people respond to failing situations suggests that the multiple determinants of escalation effects are quite different from one another. Yet, despite their differences, we view each of them as creating a self-regulatory problem. Specifically, self-justification, loss aversion, and project completion concerns can serve as a hindrance to achieving one's higher order goal of doing well in a given domain. Prior to the experience of failure, people appear to be solely motivated to perform well and show serious concerns about achieving positive outcomes. However, after obstacles are experienced and failure is encountered, people experience an intrapersonal conflict regarding how to respond. As Brockner et al. (1981) pointed out, in many everyday instances of goal-pursuit, people devote their time, money, or energy in the hope of attaining some preferred outcome in a given domain. However, once failure is encountered in that domain after a serious investment of resources has been made, individuals may come to experience a conflict between staying invested and the ultimate goal of being successful in the goal pursuit at hand. Fortunately, the current set of findings suggests that self-regulation based on action or reflection implementation intentions can effectively overcome such conflict.

It is important to note that some escalation researchers (e.g., Bragger et al., 2003) argue that continued commitment in the face of failure need not always be viewed as a problem, and instead see escalation as a rational part of decision making. According to this perspective, when uncertainty is high regarding whether failure will be followed by even more failure, people should maintain commitment in order to collect more information to resolve this uncertainty. Again, our findings are relevant, because we demonstrated that a reflection implementation intention is especially useful for starting a more complete information search when confronted with failure feedback.

\section{Future directions}

While the present research demonstrates the benefits of self-regulation via action and reflection implementation intentions in disengagement contexts, further issues still remain to be examined. For example, given that escalation tendencies tend to be stronger in situations where failure feedback is more subtle (Staw \& Ross, 1987), it would be interesting to demonstrate the effects of implementation intentions in situations that involve less clear-cut, more ambiguous feedback. Moreover, given that disengagement has been shown to be even less likely when people are not required to actively decide whether to stay with their course of action (Brockner et al., 1979), future work might also want to explore the benefits of using implementation intentions when more passive decisions are made in escalation situations. Also, given that the current set of studies provided the first examination of the effects of implementation intentions that specified reflection rather than action, future work needs to identify how exactly this reflection occurs (e.g., see Strack $\&$ Deutsch, 2004, for a possible framework).

On a broader note, future research should be devoted to discovering the specific conditions that lead people to spontaneously form specific types of implementation intentions. Oettingen, Park, and Schnetter (2001) found that the goal setting strategy of mentally contrasting a desired future with an impeding reality increased people's tendency to form implementation intentions. However, no other empirical work has directly addressed what factors lead people to develop implementation intentions on their own. This lack of research is surprising given that escalation as well as implementation intention researchers have found high rates of spontaneous usage of precommitment devices. Brockner et al. (1979), for example, found that 85\% of participants decided on their own to engage in limit setting in an escalation of commitment context, and Gollwitzer and Brandstätter (1997) found that approximately $60 \%$ of participants decided on their own to form implementation intentions when they were concerned that they might not act on their goal.

In sum, the current research shows the benefits of if-then plans that call for the assessment of one's chosen course of action or the adjustment of one's chosen course of action in escalation situations, and our findings suggest that such self-regulatory tools should be investigated more thoroughly in future disengagement work. 


\section{REFERENCES}

Aarts, H., \& Dijksterhuis, A. (2000). Habits as knowledge structures: Automaticity in goal-directed behavior. Journal of Personality and Social Psychology, 78, 53-63.

Amsel, A. (1994). Précise of frustration theory: An analysis of dispositional learning and memory. Psychonomic Bulletin and Review, 1, 280-296.

Amsel, A., \& Maltzman, I. (1950). The effect upon generalized drive strength of emotionality as inferred from the level of consummatory response. Journal of Experimental Psychology, 40, 563-569.

Amsel, A., \& Ward, J. S. (1954). Motivational properties of frustration: II. Frustration drive stimulus and frustration reduction in selective learning. Journal of Experimental Psychology, 48, 37-47.

Arkes, H. R., \& Blumer, C. (1985). The psychology of sunk cost. Organizational Behavior and Human Performance, 35 , 129-140.

Aronson, E. (1968). Dissonance theory: Progress and problems. In R. Abelson, E. Aronson, W. McGuire, T. Newcomb , M. Rosenberg , \& P. Tannenbaum (Eds.), Theories of cognitive consistency: A sourcebook (pp. 5-27). Chicago: Rand McNally.

Aspinwall, L. G., \& Richter, L. (1999). Optimism and self-mastery predict more rapid disengagement from unsolvable tasks in the presence of alternatives. Motivation and Emotion, 23, 221-245.

Bobocel, R. D., \& Meyer, J. P. (1994). Escalating commitment to a failing course of action: Separating the roles of choice and justification. Journal of Applied Psychology, 79, 360-363.

Bragger, J. D., Hantula, D. A., Bragger, D., Kirnan, J., \& Kutcher, E. (2003). When success breeds failure: History, hysteresis, and delayed exit decisions. Journal of Applied Psychology, 88, 6-14.

Brandstätter, V., \& Frank, E. (2002). Effects of deliberative and implemental mindsets on persistence in goal-directed behavior. Personality and Social Psychology Bulletin, 28, 1366-1378.

Brandstätter, V., Lengfelder, A., \& Gollwitzer, P. M. (2001). Implementation intentions and efficient action initiation. Journal of Personality and Social Psychology, 81, 946-960.

Brockner, J. (1992). The escalation of commitment to a failing course of action: Toward theoretical progress. Academy of Management Review, 17, 39-61.

Brockner, J., Rubin, J. Z., \& Lang, E. (1981). Face-saving and entrapment. Journal of Experimental Social Psychology, 17, 68-79.

Brockner, J., Shaw, M. C., \& Rubin, J. Z. (1979). Factors affecting withdrawal from an escalating commitment: Quitting before it's too late. Journal of Experimental Social Psychology, 15, 492-503.

Carver, C. S., \& Scheier, M. F. (1999). Themes and issues in the self-regulation of behavior. In R. S. Wyer, Jr. (Ed.), Advances in social cognition (Vol. 12). Mahwah, NJ: Erlbaum.

Conlon, D. E., \& Garland, H. (1993). The role of project completion information in resource allocation decisions. Academy of Management Journal, 36, 402-413.

Davis, M. A., \& Bobko, P. (1986). Contextual effects on escalation of processes in public sector decision making. Organizational Behavior and Human Decision Processes, 37, 121-138.

Dietz-Uhler, B. (1996). The escalation of commitment in political decision-making groups: A social identity approach. European Journal of Social Psychology, 26, 611-629.

Festinger, L. (1957). A theory of cognitive dissonance. Stanford, CA: Stanford University Press.

Garland, H. (1990). Throwing good money after bad: The effect of sunk costs on the decision to escalate commitment to an ongoing project. Journal of Applied Psychology, 75, 728-731.

Garland, H., \& Conlon, D. E. (1998). Too close to quit: The role of project completion in maintaining commitment. Journal of Applied Social Psychology, 28, 2025-2048.

Gollwitzer, P. M. (1990). Action phases and mind-sets. In E. T. Higgins, \& R. M. Sorrentino (Eds.), Handbook of motivation and cognition: Foundations of social behavior (Vol. 2, pp. 53-92). New York: Guilford Press.

Gollwitzer, P. M. (1993). Goal achievement: The role of intentions. European Review of Social Psychology, 4, $141-185$.

Gollwitzer, P. M. (1996). The volitional benefits of planning. In P. M. Gollwitzer, \& J. A. Bargh (Eds.), The psychology of action (pp. 287-312). New York: Guilford Press.

Gollwitzer, P. M. (1999). Implementation intentions: Strong effects of simple plans. American Psychologist, 54, $493-503$.

Gollwitzer, P. M., Bayer, U. C., \& Mc Culloch, K. C. (2005). The control of the unwanted. In R. Hassin , J. Uleman , \& J. A. Bargh (Eds.), The new unconscious (pp. 485-515). Oxford: Oxford University Press.

Gollwitzer, P. M., \& Brandstätter, V. (1997). Implementation intentions and effective goal pursuit. Journal of Personality and Social Psychology, 73, 186-199.

Gollwitzer, P. M., \& Moskowitz, G. B. (1996). Goal effects on action and cognition. In E. T. Higgins , \& A. W. Kruglanski (Eds.), Social psychology: Handbook of basic principles (pp. 361-399). New York: Guilford Press. 
Gollwitzer, P. M., \& Sheeran, P. (2006). Implementation intentions and goal achievement: A meta-analysis of effects and processes. Advances in Experimental Social Psychology, 38, 69-119.

Gollwitzer, P. M., \& Wicklund, R. A. (1985). Self-symbolizing and the neglect of others' perspectives. Journal of Personality and Social Psychology, 48, 702-715.

Heath, C. (1995). Escalation and de-escalation of commitment in response to sunk costs: The role of budgeting in mental accounting. Organizational Behavior and Human Decision Processes, 62, 38-54.

Henderson, M. D., Gollwitzer, P. M., \& Oettingen, G. (2003). Using implementation intentions to disengage from a failing course of action. Poster presented at the Society for Personality and Social Psychology. Annual Meeting, Los Angeles, California.

Hull, C. L. (1943). Principles of behavior. New York: Appleton-Century-Crofts.

Katahn, M., \& Koplin, S. T. (1966). Effects of anxiety on dominant and nondominant intratask responses: A modified replication. Psychonomic Science, 6, 159-160.

Katahn, M., \& Lyda, L. L. (1966). Anxiety and the learning of responses varying in initial rank in the response hierarchy. Journal of Personality, 34, 287-299.

Lieberman, M. D., Ochsner, K. N., Gilbert, D. T., \& Schacter, D. L. (2001). Do amnesics exhibit cognitive dissonance reduction? The role of explicit memory and attention in attitude change. Psychological Science, 121, 135-140.

Locke, E. A., \& Latham, G. P. (1990). A theory of goal setting and task performance. Englewood Cliffs, NJ: Prentice-Hall.

Lottes, I. L., DeMaris, A., \& Adler, M. A. (1996). Using and interpreting logistic regression: A guide for teachers and students. Teaching Sociology, 24, 284-298.

Luce, M. F., Bettman, J. R., \& Payne, J. W. (1997). Choice processing in emotionally difficult decisions. Journal of Experimental Psychology: Learning, Memory, and Cognition, 23, 384-405.

McCain, B. E. (1986). Continuing investment under conditions of failure: A laboratory study of the limits of escalation. Journal of Applied Psychology, 71, 280-284.

Metcalfe, J., \& Mischel, W. (1999). A hot/cool system analysis of delay of gratification: Dynamics of willpower. Psychological Review, 106, 3-19.

Moon, H. (2001a). Looking forward and looking back: Integrating completion and sunk-cost effects within an escalation-of-commitment process decision. Journal of Applied Psychology, 86, 104-113.

Moon, H. (2001b). The two faces of conscientiousness: Duty and achievement striving in escalation of commitment dilemmas. Journal of Applied Psychology, 86, 533-540.

Muraven, M., Tice, D. M., \& Baumeister, R. F. (1998). Self-control as a limited resource: Regulatory depletion patterns. Journal of Personality and Social Psychology, 74, 774-789.

Oettingen, G., Park, H., \& Schnetter, K. (2001). Self-regulation of goal setting: Turning free fantasies about the future into binding goals. Journal of Psychology and Social Psychology, 80, 736-753.

Oettingen, G., \& Thorpe, J. (2005). Fantasy realization and the bridging of time. In L. A. Sanna , \& E. C. Chang (Eds.), Judgments over time: The interplay of thoughts, feelings, and behaviors. Oxford: Oxford University Press.

Orbell, S., \& Sheeran, P. (2000). Motivational and volitional processes in action initiation: A field study of implementation intentions. Journal of Applied Social Psychology, 30, 780-797

Payne, J. W., Bettman, J. R., \& Johnson, E. J. (1988). Adaptive strategy selection in decision making. Journal of Experimental Psychology: Learning, Memory, and Cognition, 3, 534-552.

Rubin, J. Z., Brockner, J., Small-Weil, S., \& Nathanson, S. (1980). Factors affecting entry into psychological traps. Journal of Conflict Resolution, 24, 405-426.

Schaubroeck, J., \& Williams, S. (1993). Type A behavior pattern and escalating commitment. Journal of Applied Psychology, 78, 862-867.

Schoorman, D. F. (1988). Escalation bias in performance appraisals: An unintended consequence of supervisor participation in hiring decisions. Journal of Applied Psychology, 73, 58-62.

Schoorman, D. F., Mayer, R. C., Douglas, C. A., \& Hetrick, C. T. (1994). Escalation of commitment and the framing effect: An empirical investigation. Journal of Applied Social Psychology, 24, 509-528.

Sheeran, P., \& Orbell, S. (1999). Implementation intentions and repeated behaviours: Enhancing the predictive validity of the theory of planned behaviour. European Journal of Social Psychology 29, 349-369.

Sorrentino, R. M. (1973). An extension of theory of achievement motivation to the study of emergent leadership. Journal of Personality and Social Psychology, 26, 356-368.

Spence, K. W. (1956). Behavior theory and conditioning. New Haven, CT: Yale University Press.

Spence, K. W., Taylor, J. A., \& Ketchel, R. (1956). Anxiety (drive) level and degree of competition in paired-associates learning. Journal ofExperimental Psychology, 52, 306-310.

Staw, B. M. (1976). Knee-deep in the big muddy: A study of escalating commitment to a chosen course of action. Organizational Behavior and Human Performance, 16, 27-44. 
Staw, B. M., \& Fox, F. (1977). Escalation: Some determinants of commitment to a previously chosen course of action. Human Relations, 30, 431-450.

Staw, B. M., \& Ross, J. (1987). Behavior in escalation situations: Antecedents, prototypes, and solutions. In B. M. Staw , \& L. L. Cummings (Eds.), Research in organizational behavior (Vol. 9, pp. 39-78), Greenwood, CT: JAI Press.

Stone, J. (2003). Self-consistency for low self-esteem in dissonance processes: The role of self-standards. Personality and Social Psychology Bulletin, 29, 846-858.

Strack, F., \& Deutsch, R. (2004). Reflective and impulsive determinants of social behavior. Personality and Social Psychology Review, 8, 220-247.

Tan, H. T., \& Yates, J. F. (2002). Financial budgets and escalation effects. Organizational Behavior and Human Decision Processes, 87, 300-322.

Thibaut, J. W., \& Kelley, H. H. (1959). The social psychology of groups. New York: Wiley.

Verplanken, B., \& Faes, S. (1999). Good intentions, bad habits, and effects of forming implementation intentions on healthy eating. European Journal of Social Psychology, 29, 591-604.

Whyte, G. (1986). Escalating commitment to a course of action: A reinterpretation. Academy of Management Review, 11, 311-321.

Whyte, G. (1993). Escalating commitment in individual and group decision making: A prospect theory approach. Organizational Behavior and Human Decision Processes, 54, 430-455.

Wrosch, C., \& Heckhausen, J. (1999). Control processes before and after passing a developmental deadline: Activation and deactivation of intimate relationship goals. Journal of Personality and Social Psychology, 77, 415-427.

Wrosch, C., Scheier, M. F., Carver, C. S., \& Schulz, R. (2003). The importance of goal disengagement in adaptive self-regulation: When giving up is beneficial. Self and Identity, 2, 1-20.

Wrosch, C., Scheier, M. F., Miller, G. E., Schulz, R., \& Carver, C. S. (2003). Adaptive self-regulation of unattainable goals: Goal disengagement, goal reengagement, and subjective well-being. Personality and Social Psychology Bulletin, 29, 1494-1508.

Zajonc, R. B. (1965). Social facilitation. Science, 149, 269-274.

Zeigarnik, B. (1927). Das Behalten erledigter und unerledigter Handlungen. Psychologische Forschung, 9, 1-85.

Authors' biographies:

Marlone D. Henderson, PhD, Department of Psychology, University of Chicago, Illinois, USA.

Peter M. Gollwitzer, PhD, Department of Psychology, New York University, New York, USA and University of Konstanz, Konstanz, Germany.

Gabriele Oettingen, PhD, Department of Psychology, New York University, New York, USA and University of Hamburg, Hamburg, Germany.

Authors' addresses:

Marlone D. Henderson, University of Chicago, 5848 S. University Avenue, Chicago, IL 60637, USA.

Peter M. Gollwitzer and Gabriele Oettingen, New York Universtiy, 6 Washington Place, 7th Floor, New York, NY 10003, USA. 